\title{
THE VARYING EPIDEMIOLOGY OF Q FEVER IN THE SOUTH-EAST REGION OF GREAT BRITAIN
}

\section{IN AN URBAN AREA}

\author{
BY B. P. MARMION* \\ Department of Pathology, University of Cambridge \\ AND M. S. HARVEY \\ Health Department, City of Canterbury
}

(With 1 Figure and 1 Map in the Text)

Investigations of the epidemiology of $\mathrm{Q}$ fever in the inhabitants of the county of Kent have suggested that infection probably arises in the main either from sheep or from cows' milk. In order to clarify the epidemiological situation presented by the existence of these two sources of infection in one relatively small area of the country, detailed epidemiological studies of the disease have been carried out in areas in Kent in which it was probable that infection from either one or other source would predominate.

The areas chosen for such investigation were, respectively, two adjoining coastal towns in north-east Kent, and two rural areas; one in south Kent and the other, a geographically similar area intended as a control, in the country near Cambridge.

The purpose of this paper is to describe the epidemiology of $Q$ fever in the two coastal towns. A subsequent paper by Marmion \& Stoker (1956) deals with the same subject, but in two rural areas. Although the two investigations were undertaken independently, the epidemiological methods used were similar in both, and a comparison of the findings is essential to gain the maximum epidemiological information.

The two coastal towns were chosen because an earlier investigation of an outbreak of $\mathrm{Q}$ fever in a London hospital had resulted in the isolation of Rickettsia burneti from the household milk supply of a patient who had been admitted to the hospital from one of the two towns (Marmion \& Stoker, 1950). At the time it seemed reasonable to attribute his infection, and also that of some other cases of $\mathrm{Q}$ fever subsequently discovered in the towns, to the use of unpasteurized and infected milk. In succeeding years, however, the importance of infection of man by the respiratory tract after the inhalation of aerosols containing $R$. burneti has been stressed by a number of workers, in particular by those in north California (DeLay, Lennette \& DeOme, 1950; Lennette \& Clark, 1951). The latter have also pointed out that the risk of infection is limited not merely to those who encounter an aerosol in the immediate vicinity of infected and parturient animals but may also extend to persons who have no obvious direct exposure to animals. The

* Member of the staff of the Public Health Laboratory Service seconded to the Department of Pathology. 
infection of the latter group was thought, but not proved to be due to the inhalation of dust containing the rickettsia in such urban surroundings as bars, court rooms and barbers' shops, the dust being carried in from the farm animals to these places on fomites, such as, for example, the clothing of agricultural workers (Welsh, 1951; Clark, Romer, Holmes, Welsh, Lennette \& Abinanti, 1951).

The southern Californian workers in Los Angeles, who were the first to show not only that cows' milk could contain $R$. burneti, but also that it was probably responsible for human infection, considered nevertheless that some other method of infection would have to be postulated to explain the infection of those Los Angeles residents who were neither occupationally exposed nor used raw milk (Beck, Bell, Shaw \& Huebner, 1949). It has been found in England, as in Los Angeles, that $Q$ fever is by no means confined to persons consuming raw milk.

All these epidemiological considerations have combined to raise doubts in the minds of some investigators as to the part played by milk in producing infection in man (see, for example, Enright, Thomas \& Mullett, 1953).

With the recent identification of infection among sheep in Kent it was apparent that there was a reservoir of infection in the county, which, together with calving cattle, might serve for the contamination of fomites, and for the infection of town dwellers in the manner just described. It seemed desirable, therefore, to reconsider the importance of milk as a source of infection in the region, and especially in the two towns where previously it had been presumed to be the vehicle of $Q$-fever infection. Some further observations have been made on the incidence of $Q$ fever in the towns, and attention has been paid to the possibility of airborne contagion from parturient cattle or sheep. These observations, together with some from the earlier investigation, are brought together in this report.

\section{GENERAL CONSIDERATIONS AND METHODS}

\section{The towns and the hinterland}

The two towns, with populations of 18,228 and 17,200 respectively, are situated on the north-east coast of Kent. Although administratively separate, they may be considered as one because only a short stretch of open country divides them (see sketch map). On the landward side, the coastal road (A 299) forms a convenient dividing line between the towns and the surrounding country. The towns are primarily seaside holiday resorts, and the occupations of the inhabitants are for the most part connected, directly or indirectly, with the visitors or with people who have retired there. There are building depots and a thriving off-shore fishing industry, but within the boundaries of the two towns there are few factories, and, in particular, none devoted to the handling or slaughtering of animals, the packing of meat, the tanning of hides or the manufacture of glue and animal fertilizer. The handling of grain and animal feeding-stuffs is limited to a small grain elevator and bagged grain store in the harbour of one of the towns. Unlike Los Angeles, there are no dairy farms within the urban area, so that there is no close contact with dairy cattle. Although farmers and farm workers from the neighbourhood may visit the two towns, they are in no sense market towns. There is no livestock 
market, nor are there many shops dealing in farm machinery or other farm supplies. Such trading is done in the neighbouring city of Canterbury and town of Faversham. The surrounding area contains a moderate number of sheep (48 per 100 acres of crops and grass), but is not primarily a sheep-raising area as is the Romney Marsh (Marmion \& Stoker, 1956).

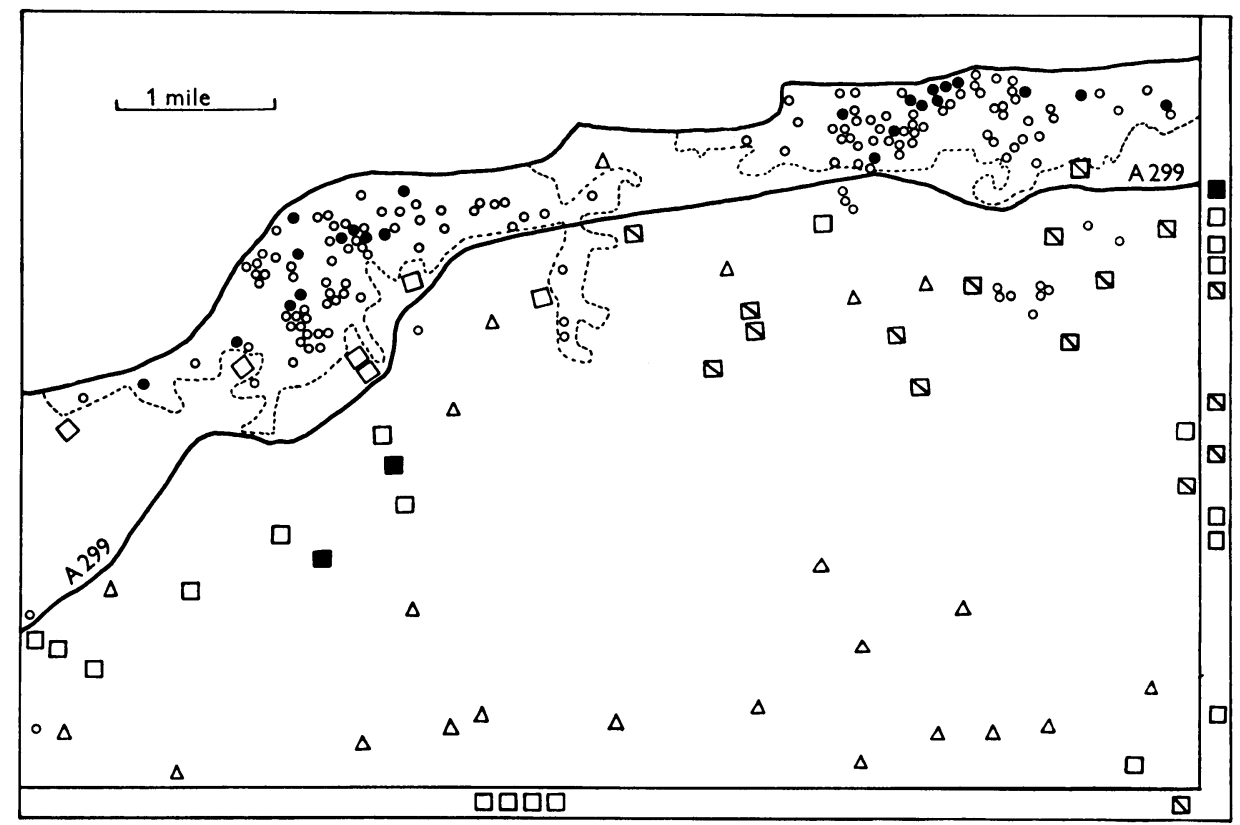

Sketch map of the area investigated. The boundaries of the two towns are indicated by a dotted line, and a road by a continuous line and a route number.

- Place of residence of patients with $Q$ fever

- Place of residence of patients with other pneumonia or fever.

- Herd milk contained $R$. burneti Position of the

$\square$ Herd milk did not contain $R$. burneti dairy herds supplying

$\checkmark$ Herd milk not tested the two towns

$\triangle$ Position of other farms.

The symbols between the double lines at the right-hand and bottom edges of the map represent dairy herds supplying the two towns but which were situated outside the area covered by the map.

\section{Epidemiological method}

The epidemiological histories of those patients who had suffered either from pneumonia or from undiagnosed fever during the period between the last months of 1948 and the first months of 1954 were determined and samples of their blood tested for the presence of complement fixing (CF) antibody to $R$. burneti, using at first the CF technique of Marmion, Rowlands, MacCallum \& Thiel (1951), and later that of Stoker, Page \& Marmion (1955).

A comparison of the patients who had probably had $Q$ fever was then made with the remainder to find out the distinctive epidemiological qualities of the former. Some of the limitations of this method are discussed at the end of the accompanying paper. 
Suitable patients for the survey were found in various ways. General medical practitioners told us about some patients who had had an illness resembling Q fever. Patients who had been notified to the Medical Officers of Health as suffering from primary pneumonia were also investigated.

Information about patients was also obtained by searching the records of three local hospitals for the names of patients who had had an illness simulating $Q$ fever. Lastly, a few persons with $Q$-fever antibody were found by testing sera from patients attending either antenatal or haematological clinics held at two local hospitals.

The nature of the investigation was then explained to this group of patients, mostly by letter but on a few occasions at a preliminary visit, and they were asked for voluntary co-operation. The possible sources of $Q$ fever were not mentioned during this first approach to the patients, so that their response was not linked in any way with their exposure to these sources or influenced by their curiosity about them. Patients who agreed to help were visited by one of five observers, and clinical and epidemiological histories were obtained in a standard manner together with a sample of blood. The patients chosen for the survey were for the most part restricted to those living within the two towns, but there were a few in the surrounding countryside (see sketch map).

With the help of the Regional Blood Transfusion Centre, Sutton, Surrey, epidemiological histories were also obtained from volunteers among blood donors who were members of the general public of the two towns and the information was correlated with the result of a test of their serum for CF antibody to $R$. burneti at a titre of 1/10 or greater. This information was obtained by a simple postal questionnaire. Finally, in order to increase the numbers of persons in the survey who had used a particular pasteurized milk supply from a large national dairy, fourteen volunteers were obtained from among the customers of one of the two local retail branches of the dairy and were interviewed and bled. (This selected groups of volunteers is not included in the data for Table 1, but is included in Table 5.)

\section{RESULTS}

A group of 446 patients who had either pneumonia or undiagnosed fever during the period 1948-54 was assembled from all sources: rather less than half agreed to take part in the investigation. The record forms and serological results of 160 of the patients were eventually completed and analysed.

\section{Clinical aspects of the series of the 160 patients}

The results of an analysis of the clinical histories can be summarized briefly by the statement that of the 160 patients, some sixty-three $(39 \%)$ had suffered from pneumonia preceded by symptoms described as a 'cold' or 'influenza'. These patients were mostly to be found among those at the extreme of life. Only one of them had Q-fever antibody at or above the chosen level (see below). Thirty-two $(20 \%)$ patients, who were without significant serological findings, had pneumonia which was clearly a complication of some predisposing pathological condition- 
long-standing asthma, chronic bronchitis and emphysema, diabetes, congestive heart failure and the like. Fifty-nine $(37 \%)$ patients had suffered from either pneumonia or undiagnosed fever as an unexpected event in an otherwise healthy life and which was not preceded by or accompanied by upper respiratory tract infection. It was among this group that the patients with the higher serum titres of complement-fixing antibody to $R$. burneti were mostly to be found. Lastly, there were six patients who could not be conveniently classified in any of these categories.

A total of twenty-two patients in the series of 160 had CF antibody to $R$. burneti at serum titres of $1 / 40$ or more-levels which previous experience suggests are usually associated with a clinical attack of $\mathrm{Q}$ fever. An additional patient, the source of the outbreak in a London hospital, was diagnosed as having suffered from $Q$ fever on histological and epidemiological evidence (see Whittick, 1950; and Marmion \& Stoker, 1950).

The nature of the frequency distribution of the numbers of those with CF antibody to $R$. burneti at various serum titres among, on the one hand, a group of healthy blood donors living in the two towns, and, on the other hand, the patients with pneumonia or fever, is such that the chance coincidence, in any particular patient, of pneumonia or fever which was not due to $R$. burneti and CF antibody at or above a serum titre of $1 / 40$ would be rather infrequent (see Table 1).

Table 1. Distribution of serum titre of complement-fixing antibody to Rickettsia burneti among patients who had had pneumonia or undiagnosed fever and healthy blood donors

\begin{tabular}{|c|c|c|c|c|c|c|c|}
\hline & \multicolumn{7}{|c|}{ No. of persons with CF antibody at a serum titre of } \\
\hline & $<1 / 10$ & $1 / 10$ & $1 / 20$ & $1 / 40$ & $1 / 80$ & $\begin{array}{l}1 / 160 \text { or } \\
\text { greater }\end{array}$ & Total \\
\hline $\begin{array}{l}\text { Patients with pneumonia } \\
\text { or fever }\end{array}$ & 132 & 4 & 1 & 7 & 2 & 13 & $159^{*}$ \\
\hline Healthy blood donors & 221 & 12 & 5 & 2 & 0 & 0 & 240 \\
\hline
\end{tabular}

* One patient with pneumonia in the series of 160 diagnosed as $Q$ fever on other evidence (see text).

The vertical dotted line divides the non-significant titres from those accepted as significant.

Fourteen of the twenty-three patients with CF antibody at or above the level of $1 / 40$ (or other specific evidence of infection) had a history of illness which was clinically suggestive of $Q$ fever, and in fact circumstances allowed of the observation of a fourfold or greater rise in CF anti-body level during the illness of four of the patients.

Four other patients had clinical histories which were more difficult to interpret. Two of these were elderly women whose story suggested the superimposition of $\mathrm{Q}$ fever on a pre-existing chronic disease, respectively post-rheumatic valvular disease of the heart and chronic pulmonary fibrosis (without pneumonia). The other two patients had had a febrile illness accompanied by jaundice-an uncommon finding in $Q$ fever, although it has been described as occurring in about $5 \%$ of cases (Derrick, 1937; Clark, Lennette, Railsback \& Romer, 1951). 
There remain five patients out of the total of twenty-three. Two of these were elderly women, aged 70 and $\mathbf{7 4}$ years respectively, who had had an indefinite febrile illness, initially without localizing physical signs, but sufficient to send them to bed for several weeks: in one, the illness culminated in a minor stroke. A third patient, a woman aged 45 , had at first a clinically typical attack of $Q$ fever and then a period of vague disability punctuated by several feverish episodes. She had a high serum titre, $1 / 2560$, of CF antibody to $R$. burneti. The last two patients in the group of five had moderately high serum titres $(1 / 40$ and $1 / 80)$, but had experienced an illness-fever, vomiting and diarrhoea-which clinically did not suggest $Q$ fever. The evidence that these two patients, and the two previously mentioned as having had jaundice and fever, suffered from $Q$ fever is not, perhaps, as good as in the remaining nineteen of the twenty-three patients. For the sake of brevity and clarity, however, all of the twenty-three persons will now be referred to as patients who had had $\mathrm{Q}$ fever.

There were two fatalities among this collection of twenty-three persons: one was the source of the London outbreak of $Q$ fever; the other, which was in a man aged 45, was due to massive pulmonary embolism during convalescence from a severe attack of $Q$ fever.

\section{EPIDEMIOLOGY}

\section{Age and sex of patients}

Table 2 shows the age and sex distribution of patients arranged according to whether they had $Q$ fever or not. In general it can be seen, as might be expected, that the majority of the patients were in the age groups under 20 and over 50 years, as these groups bear the brunt of pneumonic illness. The cases of $Q$ fever, however, were mostly to be found among those in the middle years of life, particularly among the men, although there were also some cases among elderly women.

Table 2. Age and sex distribution of 160 patients who had suffered from pneumonia or fever, arranged according to their evidence of infection with Rickettsia burneti

\begin{tabular}{|c|c|c|c|c|c|c|}
\hline & \multicolumn{6}{|c|}{ Age in years at onset of illness } \\
\hline & \multicolumn{3}{|c|}{ Males } & \multicolumn{3}{|c|}{ Females } \\
\hline & $0-20$ & $21-50$ & $\begin{array}{c}51 \\
\text { or more }\end{array}$ & $0-20$ & $21-50$ & $\begin{array}{c}51 \\
\text { or more }\end{array}$ \\
\hline$Q$ fever & 1 & 9 & 2 & 1 & 5 & 5 \\
\hline $\begin{array}{l}\text { Other pneumonia } \\
\text { or fever }\end{array}$ & 13 & 18 & 29 & 8 & 25 & 44 \\
\hline Total & 14 & 27 & 31 & 9 & 30 & 49 \\
\hline
\end{tabular}

Effect of the length of time of residence in towns on liability to infection

Table 3 shows the distribution of 156 of the patients according to their serological state and the length of time that they had lived in the two towns (information on the length of residence was lacking in four patients). The data suggest that $Q$ fever was commoner among the recent arrivals. 


\section{Distribution of patients by the month of onset of their illness}

Fig. 1 shows the distribution of the 160 patients in the survey arranged by the month of the year in which their illness began. Those patients represented in the figure by an open square had been ill with pneumonia or fever but did not have CF antibody at a serum titre of $1 / 40$; indeed, 132 of the 137 patients in this group had serum titres of $<1 / 10$ (see Table 1 ). The blacked squares represent the patients who had had $Q$ fever.

Table 3. Relation between the length of time that 156 patients with pneumonia or fever had been living in the two towns and their serological state

\begin{tabular}{cccc} 
& \multicolumn{3}{c}{ Length of residence } \\
\cline { 2 - 3 } & 11 or more & Total \\
Other pneumonia or fever & 60 & years & $19^{*}$ \\
Total & 74 & 77 & 137 \\
* Information was lacking on four patients.
\end{tabular}

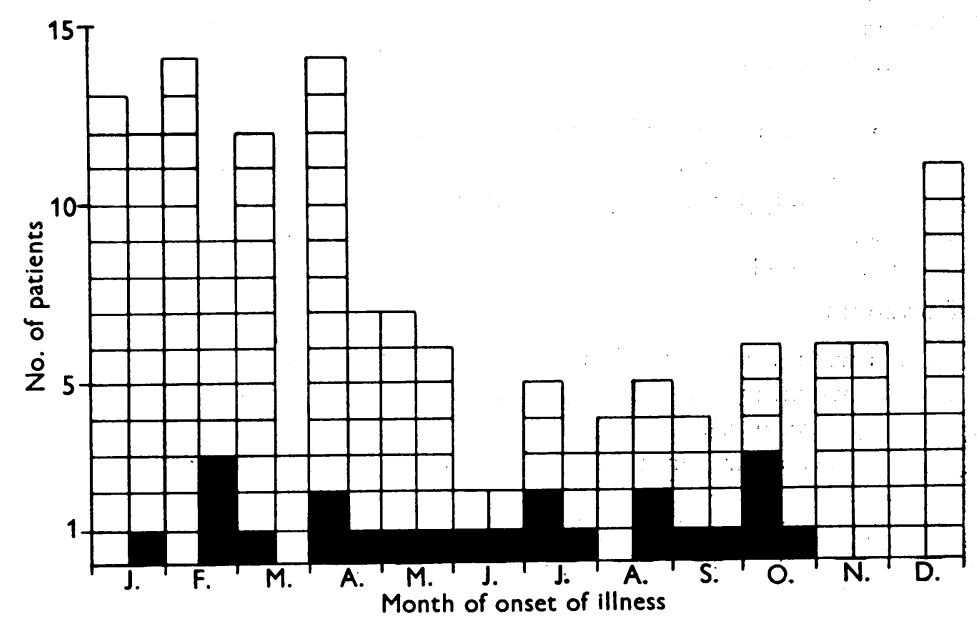

Fig. 1. Distribution of 160 patients who had either pneumonia or fever, arranged according to the month of onset of their illness and their serological state.

It can be seen from the figure that, in general, illness was commonest in the winter months. Cases of $Q$ fever, however, occurred during all the months from January to October.

The following numbers of persons were tested from among those becoming ill in each of the various years of the survey: late 1948 and during 1949 (37); 1950 (34); 1951 (28); 1952 (27); 1953 and early 1954 (34). Patients with $Q$ fever were detected in the years $1949(9) ; 1950(9)$; $1951(2) ; 1952(1)$; and $1953(2)$.

\section{Distribution of the patients by their place of residence}

The position of the homes (or other accommodation) of the patients during the period just before the onset of their illness is given in the sketch map. It is clear 
from a consideration of the map, first, that the population of the two towns was sampled fairly uniformly throughout the urban area, and secondly, that there was no particular concentration of $Q$-fever cases in any one part of the towns. It is also plain that the $Q$-fever cases did not live close to any of the dairy farms on the outskirts of the towns, or, in particular, to any of the three farms with infected herds of cattle (represented by large black squares).

\section{Occupational and other possible contacts with sources of infection}

At the time of illness the twenty-three patients with $Q$ fever had the following occupations: seven housewives (one of whom worked part-time on the land); six invalids or retired persons; a physician; two representatives of insurance companies; a window cleaner; the manager of a housing estate; an Admiralty draughtsman

Table 4. Epidemiological findings in a group of 160 patients who had suffered from either pneumonia or undiagnosed fever during the period 1948-54 arranged according to the reaction of their sera with Rickettsia burneti in the complementfixation test or other evidence of infection

\begin{tabular}{|c|c|c|}
\hline $\begin{array}{l}\text { Residence within } 200 \text { yards of potential source* } \\
\text { of infection }\end{array}$ & $0(0)$ & $18(13)$ \\
\hline $\begin{array}{l}\text { Occupational contact with potential sources of } \\
\text { infection }\end{array}$ & $1(4)$ & $4(3)$ \\
\hline $\begin{array}{l}\text { Visits to potential sources of infection or contact } \\
\text { with persons } \dagger \text { or objects from them } \\
\text { Household milk supply during the month before }\end{array}$ & $5(22)$ & $20(14)$ \\
\hline $\begin{array}{l}\text { illness : Raw } \\
\text { Pasteurized }\end{array}$ & $\underset{2}{21}(91)$ & $\begin{array}{l}92(67) \\
45\end{array}$ \\
\hline No. of patients & $23(100)$ & $137(100)$ \\
\hline
\end{tabular}

(a visitor to the towns); a sales assistant in an ironmonger's shop; a coal miner; and two school children. Only one of these persons, namely, the housewife, who also worked on the land, might be considered to have occupational contact with farms and farm animals, but, in fact, she was more concerned with potato harvesting and work with other crops. The physician, one of the insurance agents and the housing-estate manager visited farms during the course of their work, and others of the group had either visited farms during their leisure or had contact with farm workers.

Table 4 gives the results of an analysis of the various possibilities of exposure to infection of those with $\mathrm{Q}$ fever and also those without significant serological evidence of infection. These possibilities have been classified as arising in the following ways. First, because the patient's house was within 200 yards of a farm or fields where cattle or sheep were grazing or giving birth to young. Secondly, because of occupational exposure to animals or unsterilized materials from them. Thirdly, because of visits to potential sources of infection such as farms, slaughterhouses, tanneries, etc., or of contact with persons, or objects from them. 
It is evident from the information in Table 4 that a history either of living within 200 yards of a potential source of infection or of occupational contact with such sources of infection was at least no commoner among those with $Q$ fever than among the controls. A history of exposure by visits to potential sources, etc., was slightly commoner $(22 \%$ as opposed to $14 \%)$ among the Q-fever cases as compared with the controls, but the difference was not statistically significant $\left(\chi_{c}^{2}\right.$, one degree of freedom, is $0.3 ; P>0.5$ ).

The type of milk supplied to the patients' homes during the month before the onset of their illness is also given in the table. When both raw and pasteurized milk were, or could have been, supplied to a patient's home, the supply has been counted as raw. Some $90 \%$ of those with $Q$ fever had raw milk delivered to their homes at the time of their illness as compared with $67 \%$ of those suffering from pneumonia or fever which was not due to $R$. burneti $\left(\chi_{c}^{2}\right.$, one degree of freedom, is $4.5 ; P<0 \cdot 05)$. This difference is statistically significant.

In the present investigation the hypothesis was considered, as already mentioned in the introduction, that the cases of $Q$ fever in the two towns might have resulted from casual contact, in places such as shops, public houses or hairdressing saloons, between members of the general public and persons such as farmers or other workers in trades dealing with animals. This possibility obviously could not be excluded with any certainty by an interview, particularly one at a long period of time after the illness. However, it has already been shown that the group of twenty-three persons with $\mathrm{Q}$ fever did not, with the exception of the ironmonger's salesman, include persons working in shops or other places where farmers and the like would come, or those where objects and materials from farms were handled. Persons employed in such places would presumably be at greater risk than casual visitors. An analysis of the epidemiological histories of the blood donors and other adult volunteers did not reveal any significantly increased incidence of $Q$-fever antibody among those working in local shops or coming in contact with agricultural workers in other ways. Moreover, if such chance contact was invariably responsible for $Q$ fever in the two towns, then it would be reasonable to expect that the occurrence of $Q$ fever would not be linked with the use of raw or pasteurized milk in the home. In fact, as already shown, there are more raw milk users among the $Q$-fever cases than among the controls.

\section{The milk supplies of the Q-fever cases}

An examination of the epidemiological histories of the 160 patients revealed that twenty-two of the twenty-three cases of $Q$ fever had received their household milk supply from one or other of five dairies, although there were at least sixteen dairies selling milk in the two towns. The information is summarized in Table 5, in which the cases of $Q$ fever, and the other patients with pneumonia or undiagnosed fever, have been classified according to the particular retail dairy that had supplied them with milk during the month before the onset of their illness. Most of the patients with $Q$ fever were found among the customers of dairies A, B, C, D and E, even though some sixty-two patients with pneumonia or fever were sampled from those on the rounds of the other dairies in the two towns. The milk coming from certain 
స్

胥

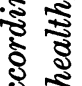

ชิ

हू ह

डे उ्ञ

ฐ ํํำ

然

ڤั

ֻั

क

8 (s)

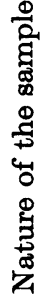

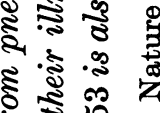

की

. స ₹

ฝे సิ च

के कूष้

ปิ ठ ะै

娄

ह है है

हิ

है क

จ

$\infty$ है

零

\%ั. है

के

\& है हี

हूँ

จ.

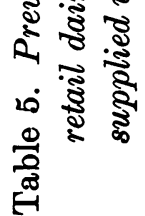

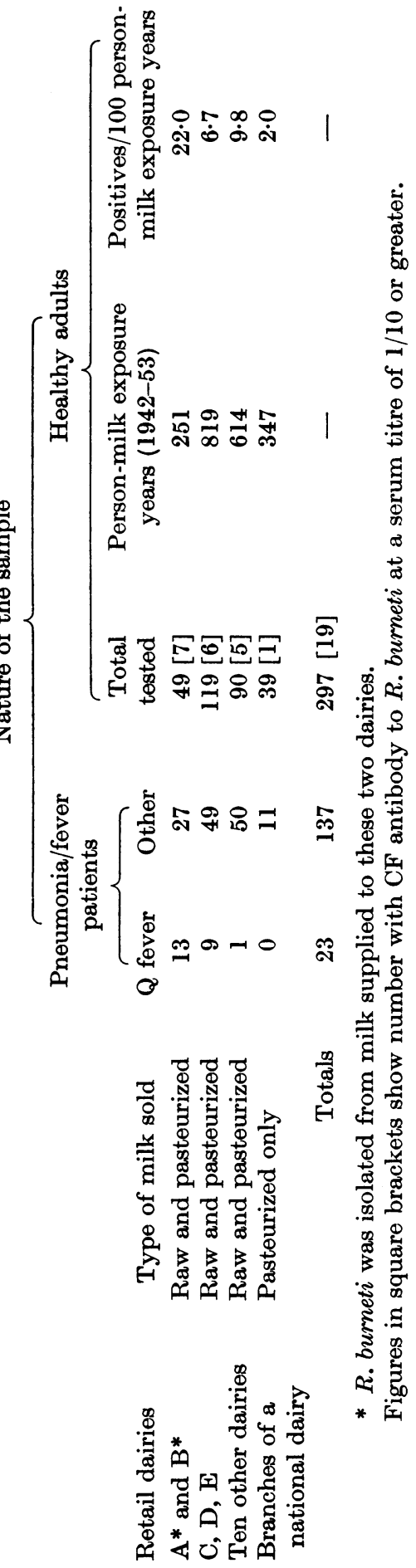


farms to the retail dairies A and B was shown on several occasions to contain $R$. burneti, and the highest proportion of $\mathrm{Q}$-fever cases was found among those patients with pneumonia or fever who used these supplies. The probability of observing such a grouping of cases by chance alone is small: the $\chi^{2}$ value (calculated with Yates' correction for continuity ; Fisher \& Yates, 1948) obtained by comparing dairies $\mathrm{A}$ and $\mathrm{B}$ and the remainder is $12 \cdot 3$, which for one degree of freedom gives $P<0 \cdot 01$.

Apart from the cases of $Q$ fever among persons using milk from dairies $A$ and $B$, it was reasonable to expect that other persons using these supplies might show evidence of subclinical infection even if they had not had overt $Q$ fever. Some information on this point was obtained from the investigation of healthy adults (mostly blood donors) living in the two towns. The questionnaire completed by these persons related to the period 1942-53, and those with CF antibody at a serum titre of $1 / 10$ or more were considered to have been infected with $R$. burneti. Histories were obtained from 254 volunteers but, as some of them had used milk from more than one dairy during the period, the total number recorded in Table 5 is rather larger. It can be seen that the number of persons with antibody is proportionately highest among those using milk from dairies $A$ and $B(7 / 49=14 \cdot 3 \%)$, although the association between the possession of antibody and the use of milk from the five dairies $\mathrm{A}$ to $\mathrm{E}$ is only approximate, and the differences in the observed prevalences of antibody in the various groups might occur not infrequently by chance alone. The information on the volunteers has also been analysed to take into account their varying length of exposure to the various milk supplies during the period 1942-53. This was done in the following way. If, for example, a volunteer had milk from dairy $\mathrm{A}$ for 8 years and then from dairy $\mathrm{C}$ for 4 years during the period 1942-53, and was also serologically positive, he (or she) would contribute 8 and 4 positive 'person-milk exposure years', respectively, to the totals of dairies A and C. The ratio of positive 'person-milk exposure years' to 100 of total 'person-milk exposure years' was then calculated for each group of dairies and is given in the last column of the table. It will be apparent that by this method of assessment the customers of dairies A and B again showed the highest incidence of serological infection. It may also be noted that those persons-either patients with pneumonia or fever or healthy adult volunteers-who had used milk from the two retail branches of a large national dairy organization which has sold only pasteurized milk since 1938, exhibited no clinical and very little subclinical evidence of infection with $R$. burneti.

\section{Dairying in the two towns}

The fifteen or so small retail dairies in the two towns were faced with a fluctuating and seasonal demand for milk because the population of the towns was greatly increased during the summer by the arrival of holiday-makers. For this and other reasons most of the dairymen sold two types of milk. One of these was heattreated milk which came by rail and which was obtained either from a London wholesaler or a large farmers' co-operative depot in Kent, or, rarely, from retailers in larger neighbouring towns. The other was raw milk brought from small farms 
in the nearby countryside and sold either as 'undesignated', or 'tuberculin-tested' milk according to the appropriate title. Apart from these small retail dairies there were two retail branches of the large national dairying organization already mentioned.

The number of retail dairies selling raw undesignated milk declined during the observation period (1948-54) (see Table 6). At the same time the number of cases of $Q$ fever also declined from eighteen in 1949 and 1950 to five in the years 1951, 1952 and 1953. This decline may merely have been coincidental, but it is possible that the change in the amount of raw milk sold in the towns (together with fluctuations in the infectivity of the milk) contributed to the effect.

Table 6. The number of small retail dairies in the two towns which were selling raw milk during the period 1949-54

$\begin{array}{lccc}\text { Rear } & \overbrace{\begin{array}{c}\text { No. of retail dairies selling } \\ \text { milk }\end{array}}^{\text {Total no. of small }} \begin{array}{c}\text { retail dairies } \\ \text { in operation }\end{array} \\ 1949 & 12 & \begin{array}{c}\text { Raw-tuberculin- } \\ \text { tested milk }\end{array} & 16 \\ 1950 & 11 & 14 & 16 \\ 1951 & 6 & 15 & 15 \\ 1952 & 5 & 10 & 15 \\ 1953-54 & 2 & 9 & 15\end{array}$

Table 7. Number of local farms supplying milk to retail dairies in the two towns and results of tests of their herds for infection with Rickettsia burneti

$\begin{array}{cccc}\text { Designation of } & \begin{array}{c}\text { No. of } \\ \text { local farms } \\ \text { associated } \\ \text { with dairy }\end{array} & \begin{array}{c}\text { No. of } \\ \text { herds tested } \\ (1949-53)\end{array} & \begin{array}{c}\text { No. with } \\ \text { in herd meti }\end{array} \\ \text { A and B } & 10 & 10 & 3 \\ \text { C, D and E } & 19 & 10 & 0 \\ \text { Ten other dairies } & 17 & 9 & 0 \\ \quad \text { Total } & 46 & 29 & 3\end{array}$

At various times during the period 1949-54 samples of the milk from the herds on some of the local farms were tested for the presence of $R$. burneti by guinea-pig inoculation with results which are shown in Table 7 . It will be seen that of twentynine dairy herds tested, three $(10 \%)$ had milks containing the rickettsia. As already shown the retail dairies $A$ and $B$, which received the infected milk from these three herds, were those associated with the most cases of $Q$ fever and subclinical infection (see Table 5). Illness or serological evidence of infection was also found among the farm workers and dairy men in immediate contact with two of these infected herds (designated W and R in Marmion \& Stoker, 1950).

\section{DISCUSSION}

The results of the reinvestigation of the epidemiological situation in the two towns support, in the main, the conclusions drawn from the previous investigation of the first cases of $Q$ fever, namely, that infected and unpasteurized milk was the vehicle 
of infection. It is not claimed, however, that necessarily all of the cases of $Q$ fever were infected from milk. Apart from the two patients who were using pasteurized milk at the time of their illness (obtained, however, from one or other of the five dairies under suspicion), there was a third person (Mr A.) who was probably infected during the outbreak of $Q$ fever in the Canterbury College of Art (Harvey, Forbes \& Marmion, 1951). Mr A. had been supplied with milk from dairy C. Members of the College of Art who were definitely involved in this outbreak and who happened to be living in one or other of the two towns have not been included in the data for the present report.

The evidence for the statement that the milk was mainly responsible for $Q$ fever in the two towns rests, from the positive aspect, on the finding of a preponderance of raw-milk users among the $Q$-fever cases as compared with the controls; on the finding that the majority of the cases and the highest proportion of those with serological evidence of infection were found among the customers of five particular dairies out of a total of sixteen or seventeen in the towns, and, lastly, on the isolation of $R$. burneti from the milk supply in two of these five dairies. From the negative aspect the fact that a history of either occupational or other regular contact with animals or animal products, or of regular contact with persons working in trades with animals, was no commoner among the $Q$-fever cases than among the controls, again directs attention to the remaining possibility of infection from milk.

The volume of raw milk sold in the two towns declined during the period of observation. As an alternative to the hypothesis of milk-borne infection it might be argued that if the cases of $Q$ fever were, in fact, due to fomites-borne infection of the type described in the introduction, and that if the risk from this declined in step with the use of raw milk, there would be an apparent but fallacious correlation between the incidence of $Q$ fever and the use of raw milk. Such an assertion would hardly explain, however, the higher incidence of the cases of $Q$ fever, and of those persons with serological evidence of infection, in the milk rounds of a few retail dairies.

The occurrence of cases of $Q$ fever throughout the year is also in agreement with the view that milk was the vehicle of infection, as the risk from this source presumably would be continuous rather than seasonal as with infection from sheep (Marmion \& Stoker, 1956). Direct infection from calving dairy cattle, which give birth in most months of the year but particularly in the spring and autumn, might, of course, be responsible for the infection of human beings at any time of the year, with, perhaps, a seasonal increase of cases in the spring and autumn. Such a pattern was not observed and, moreover, a hypothesis of direct infection from cattle is difficult to reconcile with the limitation of the $Q$-fever cases to the customers of a few dairies in the two towns.

The incidence of $Q$ fever was roughly equal in male and female patients in the two towns-twelve cases among seventy-two males and eleven among eighty-eight females. This contrasts with the preponderance of male cases in the Romney Marsh series and, once again, is presumably a reflexion of the mode of infection, as both sexes would be exposed to milk-borne infection but predominantly the men to occupational infection. 


\section{SUMMARY}

An investigation in an urban area of south-east Kent of 160 patients who had had either pneumonia or unexplained fever during the period from the end of 1948 to the beginning of 1954 revealed that twenty-three $(14 \%)$ had probably had $Q$ fever.

A comparison of the epidemiological histories of patients who had had $Q$ fever with those of the remainder showed that the use of a household supply of raw milk was commoner among the former.

Occupational exposure to animals (or animal products), visits to potentially infectious places, or residence near potential sources of infection were not significantly more frequent among the $Q$-fever cases as compared with the controls.

The isolation of Rickettsia burneti from the bulked milk of some local herds supplying retail dairies in the towns, together with the general epidemiological evidence, suggested that $Q$ fever in the towns was predominantly milk-borne.

It is a pleasure to acknowledge the help given during this investigation by our colleagues Dr G. L. Brocklehurst, Dr R. A. Begg and Dr I. F. A. Blakeney in the field and, in the laboratory, by Dr M. G. P. Stoker assisted by Miss Z. Page.

We are indebted to the general medical practitioners in the two towns for permission to approach their patients and to the patients themselves for their cooperation. Dr G. B. Forbes, of the Kent and Canterbury Hospital, helped us with the collection of blood samples and Mr F. W. I. Whitehouse and Mr C. J. Clark, sanitary inspectors in the area, gave valuable assistance at various times during the survey.

The work was undertaken as part of an investigation of $Q$ fever in Great Britain supported jointly by the Medical Research Council and the University of Cambridge.

\section{REFERENCES}

Beck, M. D., Bell, J. A., ShAw, E. W. \& Huebner, R. J. (1949). Pub. Hlth Rep., Wash., 64, 41.

Clark, W. H., Lennette, E. H., Railsback, O. C. \& Romer, M. S. (1951). Arch. intern. Med. $88,155$.

Clark, W. H., Romer, M. S., Holmes, M. A., Welsh, H. H., Lennette, E. H. \& Abinanti, F. R. (1951). Amer. J. Hyg. 54, 25.

Delay, P. D., Lennette, E. H. \& DeOme, K. B. (1950). J. Immunol. 65, 211.

Derrick, E. H. (1937). Med. J. Aust. 2, 281.

Enright, J. B., Thomas, R. C. \& Mullett, P. A. (1953). J. Milk Tech. 16, 263.

Fisher, R. A. \& YATES, F. (1948). Statistical Tables for Biological, Agricultural and Medical Research. Edinburgh: Dewer and Boyd.

Harvey, M. S., Forbes, G. B. \& Marmion, B. P. (1951). Lancet, 2, 1152.

Lennette, E. H. \& Clark, W. H. (1951). J. Amer. med. Ass. 145, 306.

Marmion, B. P., Rowlands, A., MacCallum, F. O.\& Thiel, C. C. (1951). Mon. Bull. Minist. Hlth Lab. Serv. 10, 119.

Marmion, B. P. \& Stoker, M. G. P. (1950). Lancet, 2, 611.

Marmion, B. P. \& Stoker, M. G. P. (1956). J. Hyg., Camb., 54, 547.

Stoker, M. G. P., PAge, Z. \& Marmion, B. P. (1955). Bull. Wld. Hlth Org. 13, 807.

Welsh, H. H. (1951). J. Amer. med. Ass. 145, 316.

Whiтtick, J. W. (1950). Brit. med. J. 1, 979. 